\title{
Protective effects of Tat-DJ-1 protein against streptozotocin-induced diabetes in a mice model
}

\author{
Hyeon Ji Yeo, ${ }^{1, \#}$, Eun Ji Yeo ${ }^{1, \#}$, Min Jea Shin ${ }^{1, \#}$, Yeon Joo Choi ${ }^{1}$, Chi Hern Lee ${ }^{1}$, Hyeok Yil Kwon ${ }^{2}$, Dae Won Kim ${ }^{3}$, \\ Won Sik Eum, ${ }^{1, *}$ \& Soo Young Choi ${ }^{1, *}$ \\ ${ }^{1}$ Department of Biomedical Science and Research Institute of Bioscience and Biotechnology, Hallym University, Chuncheon 24252, \\ ${ }^{2}$ Department of Physiology, College of Medicine, Hallym University, Chuncheon 24252, ${ }^{3}$ Department of Biochemistry and Molecular \\ Biology, Research Institute of Oral Sciences, College of Dentistry, Gangneung-Wonju National University, Gangneung 25457, Korea
}

\begin{abstract}
A major feature of type 1 diabetes mellitus (T1DM) is hyperglycemia and dysfunction of pancreatic $\beta$-cells. In a previous study, we have shown that Tat-DJ-1 protein inhibits pancreatic RINm5F $\beta$-cell death caused by oxidative stress. In this study, we examined effects of Tat-DJ-1 protein on streptozotocin (STZ)-induced diabetic mice. Wild type (WT) Tat-DJ-1 protein transduced into pancreas where it markedly inhibited pancreatic $\beta$-cell destruction and regulated levels of serum parameters including insulin, alkaline phosphatase (ALP), and free fatty acid (FFA) secretion. In addition, transduced WT Tat-DJ-1 protein significantly inhibited the activation of NF-KB and MAPK (ERK and p38) expression as well as expression of COX-2 and iNOS in STZ exposed pancreas. In contrast, treatment with C106A mutant Tat-DJ-1 protein showed no protective effects. Collectively, our results indicate that WT Tat-DJ-1 protein can significantly ameliorate pancreatic tissues in STZ-induced diabetes in mice. [BMB Reports 2018; 51(7): 362-367]
\end{abstract}

\section{INTRODUCTION}

Type 1 diabetes mellitus (T1DM) is characterized by destruction and dysfunction of pancreatic $\beta$-cells, leading to impaired blood glucose levels (1). DM affects about 411 million people worldwide. T1DM constitutes about $10 \%$ of all diabetes patients $(2,3)$. Diabetes also affects metabolism in various tissues, including the liver which plays an important

*Corresponding authors. Soo Young Choi, Tel: +82-33-248-2112; Fax: +82-33-248-3202; E-mail: sychoi@hallym.ac.kr; Won Sik Eum, Tel: +82-33-248-3221; Fax: +82-33-248-3202; E-mail: wseum@ hallym.ac.kr

${ }^{\text {"}}$ These authors contributed equally to this work.

https://doi.org/10.5483/BMBRep.2018.51.7.101

Received 2 May 2018, Revised 21 May 2018, Accepted 1 June 2018

Keywords: Blood glucose, Diabetes mellitus, Insulin, Protein therapy, Tat-DJ-1 role in metabolic processes as a metabolic center (4). Other studies have reported that oxidative stress and inflammation are associated with impairment of insulin levels $(5,6)$. Streptozotocin (STZ), a pancreatic $\beta$-cell toxin, is generally used to induce T1DM in animal models. An STZ-induced diabetic model affects pancreatic $\beta$-cells by hyperglycemia and free fatty acids with reduced serum insulin levels $(7,8)$.

DJ-1, a highly conserved and homodimeric protein, was initially discovered as a novel oncogene. It is extensively expressed in human tissues including brain, kidney, liver, and pancreas (9). DJ-1 plays a crucial role in protecting various cells from oxidative stress while mutant DJ-1 is known to be associated with Parkinson's disease $(10,11)$. DJ-1 protein contains cysteine residue at Cys-46 positions. C106A mutant is highly susceptible to oxidative stress. Thus, cysteine residue plays a key role in the function of DJ-1. C106A mutant also leads to the loss of function of DJ-1 protein. It is highly associated with various diseases (10-13). Several studies have shown that DJ-1 in neuronal cells can protect against cell death caused by oxidative stress (14-16).

In general, the application of proteins has many difficulties because of their molecular sizes and low permeabilities into cells. Protein transduction domains (PTDs) are known to transduce into cells or tissues. Thus, PTD fusion proteins have been used to overcome these difficulties. Many researchers have reported that various PTD fusion proteins can transduce into cells and protect cells against cell injury caused by oxidative stress in various diseases (17-21). Recently, we have demonstrated that transduced wild type (WT) Tat-DJ-1 protein can drastically protect against oxidative stress or cytokineinduced RINm5F cell death $(22,23)$. WT Tat-DJ-1 protein can reduce cell damage in oxidative stress-induced HepG2 cells. In contrast, mutant DJ-1 protein fails to protect cells (24). The function of Tat-DJ-1 protein in diabetic model is poorly understood. Thus, the objective of this study was to determine the effect of Tat-DJ-1 protein on STZ-induced diabetes in mice. 


\section{RESULTS AND DISCUSSION}

Effects of Tat-DJ-1 protein on STZ-induced diabetes in mice To determine functions of Tat-DJ-1 protein in T1DM, we prepared an experimental diabetic model using STZ according to a previous study (25). To induce diabetes in animal model, STZ is commonly used because it causes irreversible damage and leads to dysfunction of pancreatic $\beta$-cells $(7,8,26)$. Mice were divided into six groups. Immunohistochemistry staining was then performed. As shown in Fig. 1, pancreatic $\beta$-cell destruction was drastically induced in STZ-exposed mice. However, WT Tat-DJ-1 protein inhibited pancreatic $\beta$-cell destruction. WT Tat-DJ-1 protein also markedly increased insulin levels in STZ-exposed mice. In contrast, control DJ-1, C106A Tat-DJ-1, or Tat peptide had no protective effect on STZ-exposed mice.

We also determined effects of Tat-DJ-1 protein on blood glucose levels, insulin, alkaline phosphatase (ALP), and free fatty acid (FFA) secretion in STZ-induced diabetic mice (Fig. 2). In STZ-induced diabetic mice, serum insulin levels were reduced compared to those in controls. However, WT Tat-DJ-1 protein significantly increased serum insulin levels in STZ-induced diabetic mice. Blood glucose, ALP, and FFA levels in STZ-induced diabetic mice were drastically higher than those in controls whereas WT Tat-DJ-1 protein significantly decreased those levels in STZ-induced diabetic mice. However, other treated groups of STZ-exposed mice did not show changes in blood parameters. Similarly, other studies have shown that $\mathrm{DJ}-1$ protects against pancreatic $\beta$-cell death in STZ-exposed mice. In DJ-1 KO mice, insulin levels are significantly lower compared to those in STZ-treated mice (27). Other studies have shown that high glucose levels and FFA affect $\beta$-cell functionality and survival throughout the course of DM. This is called glucotoxicity. In addition, it has been reported that serum levels of ALP, AST, and ALT are increased

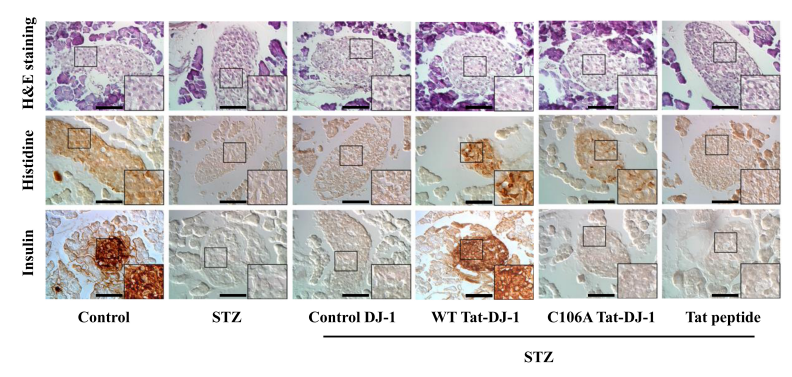

Fig. 1. Protective effects of Tat-DJ-1 protein on streptozotocin (STZ)-induced diabetes in mice. Diabetes was induced by a single intraperitoneal injection of $120 \mathrm{mg} / \mathrm{kg}$ STZ. Tat-DJ-1 protein (2 $\mathrm{mg} / \mathrm{kg}$ ) was injected three times into STZ-induced diabetic mice. Pancreatic tissue sections were stained with hematoxylin and eosin $(\mathrm{H} \& \mathrm{E})$, histidine, and insulin. Black boxes denote areas seen at higher magnification. They are presented in the lower right corner of the panel. Scale bar, $100 \mu \mathrm{m}$ (50 $\mu \mathrm{m}$ for high magnification). by hepatotoxic effect of STZ in STZ-induced diabetic animal models (28-31).

\section{Effects of Tat-DJ-1 protein on MAPK signaling pathway in pancreas}

Previous studies have showed that DJ-1 can regulate various cell signaling pathways, including mitogen activated protein kinase (MAPK), phosphatidylinositol-3-kinase (PI3K)/Akt, and apoptosis signal-regulating kinase (ASK1) that regulate cell survival or cell death (32-35). Other reports have also suggested that diabetic nephropathy (DN), one of prevalent complications associated with diabetes, involves nuclear factor kappa B (NF-KB) and MAPK (36). We determined whether this protein might regulate MAPK and NF-KB in STZ-exposed pancreas. As shown in Fig. 3A, phosphorylation levels of ERK and p38 protein were higher in the pancreases of STZ-exposed mice compared to those in control mice. WT Tat-DJ-1 protein markedly reduced phosphorylation levels of ERK and p38 proteins in STZ-exposed mice. However, we did not detect JNK expression levels in this study (data not shown). Our results also showed that phosphorylation levels of $I \kappa B \alpha$ and p65 in pancreases of STZ-exposed mice were higher than those in control mice. WT Tat-DJ-1 protein reduced phosphorylation levels of IKB $\alpha$ and p65 levels in STZ-exposed mice (Fig. 3B). In contrast, other treatments did not affect signaling pathways in STZ-exposed mice. Consistent with
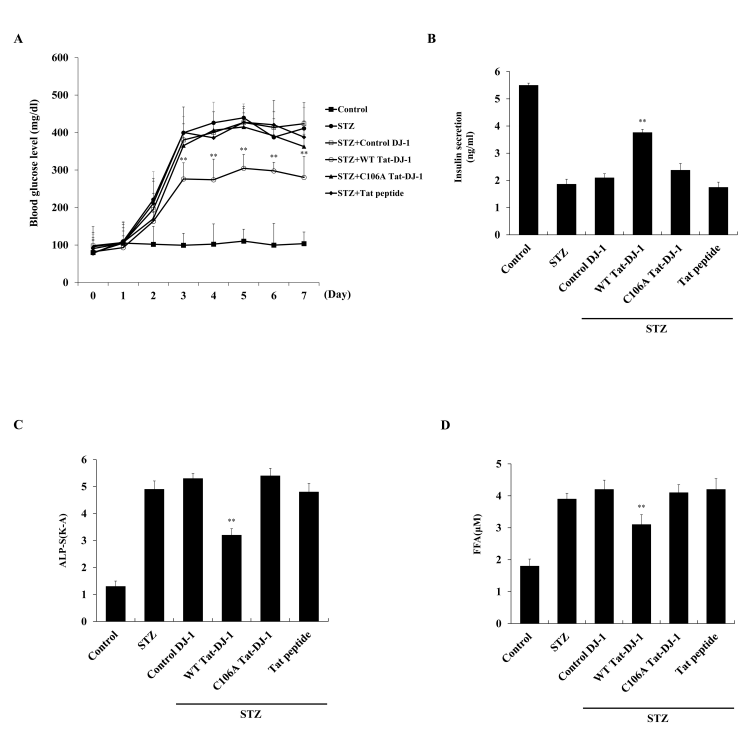

Fig. 2. Effects of Tat-DJ-1 protein on blood parameters in STZ-induced diabetic mice. Diabetes was induced by a single intraperitoneal injection of $120 \mathrm{mg} / \mathrm{kg} \mathrm{STZ}$. Tat-DJ-1 protein (2 $\mathrm{mg} / \mathrm{kg}$ ) was injected three times into mice with STZ-induced diabetes. Changes in levels of blood glucose (A), serum insulin (B), alkaline phosphatase (ALP) (C), and free fatty acid (FFA) (D) were determined using respective assay kits. $* * P<0.01$ versus relevant STZ-induced diabetic group. 

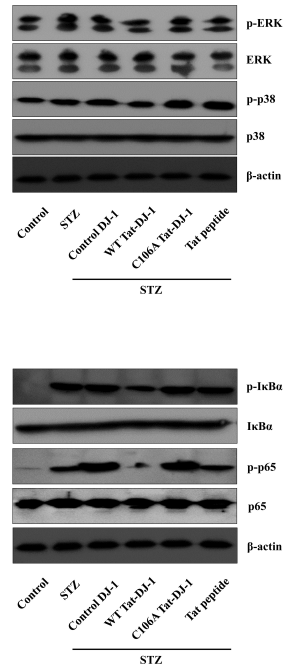
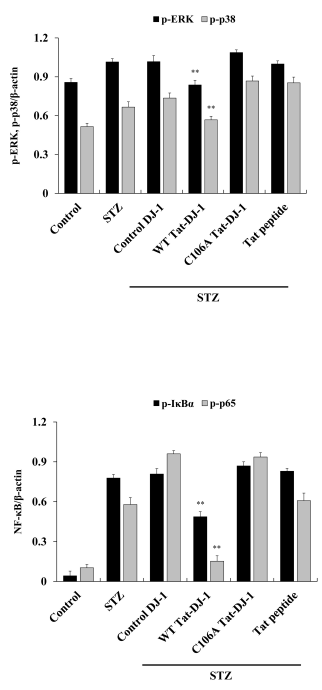

Fig. 3. Effects of Tat-DJ-1 protein on STZ-induced MAPK and NF- $K B$ activation in pancreas. Diabetes was induced by a single intraperitoneal injection of $120 \mathrm{mg} / \mathrm{kg}$ STZ. Tat-DJ-1 protein (2 $\mathrm{mg} / \mathrm{kg}$ ) was injected three times into mice with STZ-induced diabetes. Activation of MAPK (A) and NF-KB (B) was determined by Western blot analysis and the band intensity was measured by densitometry. $* * \mathrm{P}<0.01$ versus relevant STZ-induced diabetic group.

these results, our previous studies have shown that transduced Tat-DJ-1 protein inhibits oxidative stress-induced RINm5F and HepG2 cell death by regulating MAPK and NF-KB activation $(23,24)$. Recently studies have shown that phosphorylation levels of MAPKs are increased in STZ-exposed rats whereas treatment with ginsenoside (GSS) exerts protective effects against T1DM via regulating MAPKs activation (37). Zhang et al. (38) have also shown that lentinan (LNT) used in traditional medicine can suppress MAPK (JNK and p38) and NF-KB activation in STZ-exposed INS-1 cells.

\section{Tat-DJ-1 protein inhibits STZ-induced inflammation in pancreas}

Accumulating evidence suggests that the development of T1DM or DN will lead to inflammation (39-41). Proinflammatory cytokines and oxidative stress are known to trigger pancreatic $\beta$-cell death (42-44). As shown in Fig. 4, COX-2 and iNOS expression levels were increased in STZ-treated mice compared to those in normal control mice. WT Tat-DJ-1 protein markedly reduced expression levels of these proteins whereas mice in other treatment groups did not show any significant changes in these expression levels compared to STZ-exposed mice. Kellogg et al. (45) have shown that COX-2 can lead to destruction of pancreatic tissues in diabetes, suggesting that regulating COX-2 pathway is a potential therapeutic strategy to control diabetic peripheral
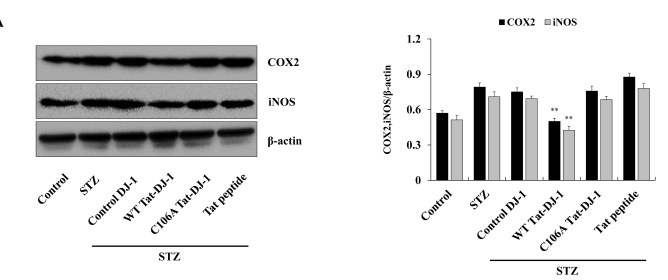

в

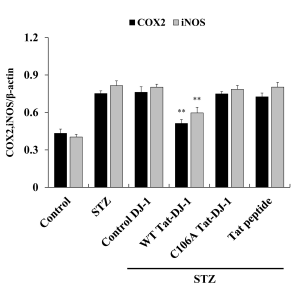

Fig. 4. Effects of Tat-DJ-1 protein on STZ-induced inflammatory response in pancreas. Diabetes was induced by a single intraperitoneal injection of $120 \mathrm{mg} / \mathrm{kg} \mathrm{STZ}$. Tat-DJ-1 protein $(2 \mathrm{mg} / \mathrm{kg}$ ) was injected three times into mice with STZ-induced diabetes. Expression levels of COX-2 and iNOS protein (A) and mRNA (B) were determined by Western blotting and RT-PCR analysis. Band intensity was measured by densitometry. ${ }^{* * P}<0.01$ versus relevant STZ-induced diabetic group.

neuropathy. Several studies have shown that COX-2 and iNOS inhibitors can effectively alleviate diabetic neuropathic pain in STZ-induced neuropathy (46). COX-2 and iNOS also contribute to STZ-induced diabetic hyperalgesia. COX-2 and iNOS inhibitors can suppress hyperalgesia occurring in STZ-exposed rats (47).

In summary, our study demonstrated that transduced WT Tat-DJ-1 protein could attenuate STZ-induced diabetes by suppressing changes of blood parameters, MAPK and NF-KB signaling pathways, and inflammatory responses. In contrast, mutant Tat-DJ-1 protein did not show protective effects in STZ-exposed mice. Our results indicate that WT Tat-DJ-1 protein may represent a useful therapeutic agent for T1DM. However, further study is still needed to explore its potential applications.

\section{MATERIALS AND METHODS}

\section{Materials}

Primary and HRP-conjugated secondary antibodies were obtained from Santa Cruz Biotechnology (Santa Cruz, CA, USA) and Cell Signaling Technology (Beverly, MA, USA). Tat peptides were purchased from PEPTRON (Daejeon, Korea). WT Tat-DJ-1, C106A Tat-DJ-1, and control DJ-1 protein were prepared in our laboratory as described previously $(23,24)$. Male ICR mice were obtained from the Experimental Animal Center at Hallym University. All other agents were of the highest grade available unless otherwise stated. 


\section{Animals and experimental protocol}

Male ICR mice at 6-week-old were housed at constant temperature of $23^{\circ} \mathrm{C}$ and relative humidity of $60 \%$ with a fixed $12 \mathrm{~h}$ light: $12 \mathrm{~h}$ dark cycle. They were provided free access to food and water. All experimental procedures involving animals and their care conformed to the Guide for the Care and Use of Laboratory Animals of the National Veterinary Research \& Quarantine Service of Korea. They were approved by the Hallym Medical Center Institutional Animal Care and Use Committee (Permit No. Hallym 2015-17).

To examine effects of Tat-DJ-1 protein on STZ-induced diabetic mice, mice were divided into six groups $(n=7$ per group): 1) non-diabetic normal control mice; 2) STZ-induced diabetic mice; 3) STZ + control DJ-1 protein treated mice; 4) STZ + WT Tat-DJ-1 protein treated mice; 5) STZ + C106A Tat-DJ-1 protein treated mice; and 6) STZ + Tat peptide treated mice. Diabetes was induced by STZ as described previously (25). Diabetic mice received intraperitoneal injections of STZ (120 mg/kg) dissolved in $50 \mathrm{mM}$ citrate buffer $(\mathrm{pH} 4.5)$ whereas normal control mice were given citrate buffer. These mice received three injections of WT Tat-DJ-1 protein $(2 \mathrm{mg} / \mathrm{kg})$ at 1,3 and 5 days, C106A Tat-DJ-1 protein $(2 \mathrm{mg} / \mathrm{kg})$, control DJ-1 protein $(2 \mathrm{mg} / \mathrm{kg})$, or Tat peptide $(2 \mathrm{mg} / \mathrm{kg}$ ). Mice were sacrificed by cervical dislocation at 7 days after the induction of diabetes with STZ. Pancreatic tissues were removed for histological examinations. To analyze pancreatic $\beta$-cells, tissue sections were incubated with either an anti-mouse insulin IgG (dilution 1:300; InnoGenex, San Ramon, CA, USA) or anti-His (dilution 1:200). Pancreatic tissue sections were stained with a peroxidase/3,3'-diaminobenzidine (DAB) system kit (Dako EnVision kit; Dako, Glostrup, Denmark) or hematoxylin and eosin (H\&E; Sigma-Aldrich) as previously described (48).

\section{Blood analytical measurements}

Changes in blood glucose levels were analyzed using Accu-Chek glucose strips and Accu-Chek compact plus meter (Roche, Germany). To minimize effects of diurnal fluctuations, blood samples were collected from tail veins at the same time every day. Serum insulin (Shibayagi, Japan), alkaline phosphatase (ALP; Asan Pharmaceutical, Korea), and free fatty acid (FFA; Bioassay system, USA) levels were measured using commercially available assay kits.

\section{Western blot analysis}

Pancreas biopsies were homogenized vigorously in tissue protein extraction buffer with a protease inhibitor cocktail. Samples of equal amounts of proteins were subjected to $12 \%$ SDS-PAGE and transferred to nitrocellulose membranes. These membrane were blocked with $5 \%$ nonfat dry milk in TBST buffer ( $25 \mathrm{mM}$ Tris- $\mathrm{HCl}, 140 \mathrm{mM} \mathrm{NaCl}, 0.1 \%$ Tween 20, $\mathrm{pH}$ 7.5) for $1 \mathrm{~h}$. Membranes were then incubated with primary

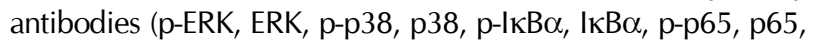
COX-2, iNOS, $\beta$-actin) and HRP-conjugated secondary antibodies. Protein bands were detected using enhanced chemiluminescent reagents (Amersham, Franklin Lakes, NJ, USA) (49).

\section{Reverse Transcription (RT)-PCR analysis}

Total RNA was isolated from pancreas biopsy sample using an Easy blue kit (Invitrogen, Carlsbad, CA, USA) according to the manufacturer's instructions. RNA (1 $\mu \mathrm{g})$ was reversibly transcribed and cDNA aliquots were amplified with COX-2, iNOS, and $\beta$-actin primers: COX-2 antisense, $5^{\prime}$-TGGACGAGGTTTTT CCACCAG-3'; COX-2 sense, 5'-CAAAGGCCTCCATTGACCA GA-3'; iNOS antisense, 5'-CTGTCAGAGCCTCGTGGCTTT-3'; iNOS sense, 5'-ATGGCTCGGGATGTGGCTAC-3'; $\beta$-actin antisense, 5'-GGACAGTGAGGCCAGGATGG-3'; $\beta$-actin sense, 5'-AGTGTGACGTTGACATCCGTAAAGA-3'. A PCR Premix kit (Intron Biotechnology, Seoul, Korea) was used to perform PCR. PCR products were resolved on $1 \%$ agarose gel after ethidium bromide staining. They were visualized with ultraviolet light (50).

\section{Statistical analysis}

Differences between groups were analyzed by one-way analysis of variance followed by Bonferroni's post-hoc test using GraphPad Prism software (version 5.01; GraphPad Software Inc., San Diego, CA, USA). ${ }^{* * P}<0.01$ was considered to indicate statistically significant difference.

\section{ACKNOWLEDGEMENTS}

This work was supported by grant (2014R1A1A4A01008026 and (2016R1D1A3B03932554) through the National Research Foundation (NRF) funded by the Ministry of Education, Republic of Korea. It was also supported by a Priority Research Center Program grant (NRF-2009-0093812) through the National Research Foundation funded by the Ministry of Science, ICT (MSIT), Republic of Korea.

\section{CONFLICTS OF INTEREST}

The authors have no conflicting interests.

\section{REFERENCES}

1. Lukic ML, Pejnovic N and Lukic A (2014) New insight into early events in type 1 diabetes: role for islet stem cell exosomes. Diabetes 63, 835-837

2. Daneman D (2006) Type 1 diabetes. Lancet $367,847-858$

3. Welters A and Lammert E (2014) Diabetes Mellitus. In: Lammert E, Zeeb M (eds) Metabolism of human diseases: organ physiology and pathophysiology. Springer, Vienna, $163-173$

4. Rui L (2014) Energy metabolism in the liver. Compr Physiol 4, 177-197

5. Fiorentino TV, Prioletta A, Zuo P and Folli F (2013) Hyperglycemia-induced oxidative stress and its role in diabetes mellitus related cardiovascular diseases. Curr 
Pharm Des 19, 5695-5703

6. Esposito K, Marfella R and Giugliano D (2003) Stress hyperglycemia, inflammation, and cardiovascular events. Diabetes Care 26, 1650-1651

7. Hayashi K, Kojima R and Ito M (2006) Strain differences in the diabetogenic activity of streptozotocin in mice. Biol Pharm Bull 29, 1110-1119

8. Mikio I, Yoichi K, Akiko N, Koji H and Atsuhiko N (2001) Characterization of low dose streptozotocin-induced progressive diabetes in mice. Environ Toxicol Pharmacol 9, 71-78

9. Nagakubo D, Taira T, Kitaura $\mathrm{H}$ et al (1997) DJ-1, a novel oncogene which transforms mouse NIH3T3 cells in cooperation with ras. Biochem Biophys Res Commun 231, 509-513

10. Wilson MA (2011) The role of cysteine oxidation in DJ-1 function and dysfunction. Antioxid Redox Signal 15, 111-122

11. Ariga $\mathrm{H}$, Takahashi-Niki $\mathrm{K}$, Kato I, Maita $\mathrm{H}$, Niki $\mathrm{T}$ and Iguchi-Ariga SM (2013) Neuroprotective function of DJ-1 in Parkinson's disease. Oxidative Med Cell Longev 2013, 683920

12. Bonifati V, Rizzu P, van Baren MJ et al (2003) Mutations in the DJ-1 gene associated with autosomal recessive early-onset parkinsonism. Science 299, 256-259

13. Jain D, Jain R, Eberhard D et al (2012) Age- and diet-dependent requirement of DJ-1 for glucose homeostasis in mice with implications for human type 2 diabetes. J Mol Cell Biol 4, 221-230

14. $\mathrm{Yu} \mathrm{HH}, \mathrm{Xu} \mathrm{Q}$, Chen HP et al (2013) Stable overexpression of DJ-1 protects $\mathrm{H} 9 \mathrm{c} 2$ cells against oxidative stress under a hypoxia condition. Cell Biochem Funct 31, 643-651

15. Inden M, Taira T, Kitamura $Y$ et al (2006) PARK7 DJ-1 protects against degeneration of nigral dopaminergic neurons in Parkinson's disease rat model. Neurobiol Dis $24,144-158$

16. Kim RH, Smith PD, Aleyashin $\mathrm{H}$ et al (2005) Hypersensitive of DJ-1-deficient mice to 1-methtyl-4-phenyl1,2,3,6-tetrahydropyrindine (MPTP) and oxidative stress. Proc Natl Acad Sci U S A 102, 5215-5220

17. Wadia JS and Dowdy SF (2002) Protein transduction technology. Curr Opin Biotechnol 13, 52-56

18. van den Berg A and Dowdy SF (2011) Protein transduction domain delivery of therapeutic macromolecules. Curr Opin Biotechnol 22, 888-893

19. Kubo E, Fatma N, Akagi Y, Beier DR, Singh SP and Singh DP (2008) TAT-mediated PRDX6 protein transduction protects against eye lens epithelial cell death and delays lens opacity. Am J Physiol Cell Physiol 294, C842-C855

20. Embury J, Klein D, Pileggi A et al (2001) Proteins linked to a protein transduction domain efficiently transduce pancreatic islets. Diabetes 50, 1706-1713

21. Jo HS, Eum WS, Park EY et al (2017) Effects of PEP-1-FK506BP on cyst formation in polycystic kidney disease. BMB Rep 50, 460-465

22. Jo HS, Yeo HJ, Cha JH et al (2016) Transduced Tat-DJ-1 protein inhibits cytokine-induced pancreatic RINm5F cell death. BMB Rep 49, 297-302

23. Jo HS, Cha HJ, Kim SJ et al (2016) Tat-DJ-1 inhibits oxidative stress-mediated RINm5F cell death through suppression of NF-KB and MAPK activation. Med Chem Res 25, 2589-2598

24. Jo HS, Yeo EJ, Shin MJ et al (2017) Tat-DJ-1 enhances cell survival by inhibition of oxidative stress, NF-KB and MAPK activation in HepG2 cells. Biotechnol Lett 39, 511-521

25. Kim MJ, Kim DW, Lee BY et al (2013) Transduced Tat-glyoxalase protein attenuates streptozotocin-induced diabetes in a mouse model. Biochem Biophys Res Commun 430, 294-300

26. Szkudelski T (2001) The mechanisms of alloxan and streptozotocin action in $\beta$-cells of rat pancreas. Physiol Res 50, 536-546

27. Jain D, Weber G, Eberhard D et al (2015) DJ-1 protects pancreatic beta cells from cytokine- and streptozotocinmediated cell death. PLoS One 10, e0138535

28. Robertson RP (2009) Beta-cell deterioration during diabetes: what's in the gun? Trends Endocrinol Metab 20, 388-393

29. Mota M, Banini BA, Cazanave SC and Sanyal AJ (2016) Molecular mechanism of lipotoxicity and glucotoxicity in nonalcoholic fatty liver disease. Metabolism 65, 1049-1061

30. Navarro C, Montilla P, Martin A, Jimenez J and Utrilla P (1993) Free radicals scavenger and antihepatotoxic activity of Rosmarinus. Planta Med 59, 312-314

31. Singh R, Bhardwaj P and Sharma P (2013) Antioxidant and toxicological evaluation of Cassia sopherain streptozotocin-induced diabetic Wister rats. Pharmacognosy Res $5,225-232$

32. Ren H, Fu K, Mu C, Li B, Wang D and Wang G (2010) DJ-1, a cancer and Parkinson's disease associated protein, regulates autophagy through JNK pathway in cancer cells. Cancer Lett 297, 101-108

33. Gu L, Cui T, Fan C et al (2009) Involvement of ERK1/2 signaling pathway in DJ-1-induced neuroprotection against oxidative stress. Biochem Biophys Res Commun 383, 469-474

34. Im JY, Lee KW, Junn E and Mouradian MM (2010) DJ-1 protects against oxidative damage by regulating the thioredoxin/ASK1 complex. Neurosci Res 67, 203-208

35. Jaramillo-Gomez J, Nino A, Arboleda $\mathrm{H}$ and Arboleda G (2015) Overexpression of DJ-1 protects against C2-ceramide-induced neuronal death through activation of the PI3K/AKT pathway and inhibition of autophagy. Neurosci Lett 603, 71-76

36. Sakai N, Wada T, Furuichi K et al (2002) p38 MAPK phosphorylation and NF-kappa B activation in human crescentic glomerulonephritis. Nephrol Dial Transplant 17, 998-1004

37. Shi $Y$, Wan $X$, Shao $N$, Ye R, Zhang $N$ and Zhang $Y$ (2016) Protective and anti-angiopathy effects of ginsenoside Re against diabetes mellitus via the activation of p38MAPK, ERK1/2 and JNK signaling. Mol Med Rep 14, 4849-4856

38. Zhang $Y$, Mei $H$, Shan $W$ et al (2016) Lentinan protects pancreatic $\beta$ cells from STZ-induced damage. J Cell Mol Med 20, 1803-1812

39. Sakai N, Wada T, Furuichi K et al (2005) Involvement of extracellular signal-regulated kinase and p38 in human diabetic nephropathy. Am J Kidney Dis 45, 54-65 
40. Weih F, Carrasco D, Durham SK et al (1995) Multiorgan inflammation and hematopoietic abnormalities in mice with a targeted disruption of RelB, a member of the NF- $\beta B /$ Rel family. Cell 80, 331-340

41. Mollah ZH, Pai S, Moore C et al (2008) Abnormal NF-kappa B function characterizes human type 1 diabetes dendritic cells and monocytes. J Immunol 180, 3166-3175

42. Lundh M, Scully SS, Mandrup-Poulsen T and Wagner BK (2013) Small-molecule inhibition of inflammatory beta cell death. Diabetes Obes Metab 15, 176-184

43. Donath MY and Shoelson SE (2011) Type 2 diabetes as an inflammatory disease. Nat Rev Immunol 11, 98-107

44. Rabinovitch A and Suarez-Pinzon WL (1998) Cytokines and their roles in pancreatic islet beta-cell destruction and insulin-dependent diabetes mellitus. Biochem Pharmacol 55, 1139-1149

45. Kellogg AP, Cheng HT and Pop-Busui R (2008) Cyclooxygenase-2 pathway as a potential therapeutic target in diabetic peripheral neuropathy. Curr Drug Targets 9, 68-76

46. Bujalska-Zadrozny M, de Corde A and Pawlik K (2015)
Influence of nitric oxide synthase or cyclooxygenase inhibitors on cannabinosids activity in streptozotocininduced neuropathy. Pharmacol Rep 67, 209-216

47. Bujalska M, Tatarkiewicz J, de Corde A and Gumulka SW (2008) Effects of cyclooxygenase and nitric oxide synthase inhibitors on streptozotocin-induced hyperalgesia in rats. Pharmacol 81, 151-157

48. Ahn EH, Kim DW, Shin MJ et al (2016) Tat-ATOX1 inhibits streptozotocin-induced cell death in pancreatic RINm5F cells and attenuates diabetes in a mouse model. Int J Mol Med 38, 217-224

49. Yang SJ, Kim J, Lee SE, Ahn JY, Choi SY and Cho SW (2017) Anti-inflammatory and anti-oxidative effects of 3-(naphthalen-2-yl(propoxy)methyl)azetidine hydrochloride on $\beta$-amyloid-induced microglial activation. BMB Rep 50, 634-639

50. An SY, Youn GS, Kim HJ, Choi SY and Park J (2017) Celastrol suppresses expression of adhesion molecules and chemokines by inhibiting JNK-STAT1/NF-кB activation in poly(l:C)-stimulated astrocytes. BMB Rep 50, 25-30 